\title{
Influence of Polyamide Membrane Surface Chemistry on Gypsum Scaling Behavior
}

\author{
Devin L. Shaffer, ${ }^{a}$ Marissa E. Tousley, ${ }^{\mathrm{b}}$ Menachem Elimelech ${ }^{\mathrm{a}^{*}}$
}

submitted to Journal of Membrane Science

August 22, 2016

${ }^{a}$ Department of Chemical \& Environmental Engineering, Yale University, New Haven, CT 06520-8286, USA

${ }^{b}$ Department of Chemical Engineering, Rose-Hulman Institute of Technology, Terre Haute, IN 47803, USA

* Corresponding author. M. Elimelech. Tel.: 203432 2789; fax: 203432 2881. E-mail address: menachem.elimelech@yale.edu 


\begin{abstract}
Mineral scaling of thin-film composite desalination membranes is affected by the surface chemistry and roughness of the membrane polyamide selective layer, but the relative contributions of these surface properties to scaling is unknown. We studied the influence of differences in polyamide surface chemistry on gypsum (calcium sulfate dihydrate) scaling of thin-film composite membranes, independent of surface roughness, with the goal of improving scaling resistance through changes to membrane surface chemistry. Smooth polyamide films and thin-film composite membranes were created using a molecular layer-by-layer deposition technique, and the surface chemistry of the polyamide films was enriched with amine or carboxyl functional groups by varying the final monomer deposition step in the layer-by-layer assembly process. Polyamide films and composite membranes with different surface chemistry were subjected to gypsum scaling by both homogeneous and heterogeneous nucleation mechanisms. Results from quartz crystal microbalance experiments and dynamic membrane scaling tests show that differences in the polyamide surface chemistry do not influence long-term gypsum scaling behavior. We conclude that membrane surface roughness and hydrodynamic conditions have a greater effect than differences in surface chemistry on the gypsum scaling behavior of polyamide thin-film composite membranes.
\end{abstract}

Keywords: polyamide, gypsum, scaling, membrane, layer-by-layer

\title{
1. Introduction
}

Mineral scaling is an important consideration for membrane desalination applications. Scaling, like other forms of fouling, reduces productivity, degrades permeate water quality [1], and is costly to control and mitigate [2,3]. Scaling is especially problematic in inland desalination applications, such as brackish water reverse osmosis [4], desalination of oil and gas produced water [5], and treatment of agricultural drainage water [6, 7]. In these applications, high recovery rates are critical because disposal options for the membrane concentrate are often limited and costly $[5,6]$. However, operating at high recovery has the potential to cause membrane scaling, especially for feed waters like brackish groundwater, which often has high concentrations of scale-forming ions like calcium, carbonate, and sulfate $[4,8]$. Calcium sulfate 
dihydrate (gypsum, $\mathrm{CaSO}_{4} \cdot 2 \mathrm{H}_{2} \mathrm{O}$ ), in particular, is a significant scaling concern because of its prevalence in many source waters, the insensitivity of gypsum to scaling control by $\mathrm{pH}$ adjustment [9], and the relative difficulty in removing the deposited scale [2].

Scaling can occur by homogeneous nucleation and crystal growth in a saturated feed solution followed by deposition of the scalant crystals onto the membrane surface (bulk deposition) or by heterogeneous nucleation on energetically favorable sites on the membrane surface followed by crystal growth (surface crystallization) [2]. Scaling behavior in membrane desalination is a function of the feed solution chemistry, membrane surface characteristics, and the system hydrodynamics [10]. This coupling between physical and chemical interactions in a desalination system dictates the occurrence, mechanism, and severity of scaling.

Thin-film composite (TFC) membranes, which are the standard for membrane desalination, are prone to fouling and scaling because of their rough, heterogeneous surfaces [11]. These membranes are fabricated through the interfacial polymerization of trimesoyl chloride (TMC) and $m$-phenylene diamine (MPD) monomers to form a thin crosslinked polyamide selective layer over a thicker porous support layer $[11,12]$. Mineral scaling in both reverse osmosis and forward osmosis desalination is affected by a combination of membrane surface roughness and surface chemistry, but the relative contributions of these surface properties to membrane scaling propensity is unknown.

Surface roughness, including the height, morphology, and separation of membrane roughness features, clearly influences membrane scaling. Pilot-scale desalination studies [13] and benchscale experiments $[14,15]$ have demonstrated that smoother membrane surfaces experience less scaling than rougher membranes, and modifying polyamide membranes to reduce their surface roughness also reduces their scaling propensity [16]. Studies of gypsum scaling kinetics for polymeric films and polyamide membrane surfaces of different roughness morphologies have shown that rougher surfaces generally experienced more scaling [17], though the scaling propensity could not be correlated directly to the degree of surface roughness [18]. The size and separation distance of surface roughness features also influence scaling behavior [18]. 
The influence of polyamide surface chemistry on membrane scaling is not as well established as that of surface roughness. Isolating the effects of surface chemistry is challenging because of the roughness and chemical heterogeneity inherent to interfacially-polymerized TFC polyamide membranes [19]. Bench-scale studies of membrane scaling in forward osmosis desalination have proposed that a high density of carboxyl functional groups on the polyamide surface of a thinfilm composite membrane [14] or carboxyl groups due to adsorbed foulants [20] enhance gypsum scaling by surface crystallization when compared to a smoother, uncharged cellulose acetate membrane. These results may reflect the influence of surface roughness in addition to that of surface chemistry. A different study of gypsum scaling during forward osmosis desalination indicated that membrane surface charge was the dominant property affecting scaling propensity [21]. Studies of the scaling kinetics on more controlled polymer films [17] and monolayer surfaces [22] have demonstrated that surface chemistry can affect mineral scaling behavior, with uncharged [17, 22] and mixed charge [22] surfaces experiencing reduced scaling compared to charged surfaces. For desalination membranes, the role of polyamide selective layer chemistry in promoting or resisting mineral scaling remains unclear.

We applied molecular layer-by-layer (mLbL) deposition techniques to study how differences in polyamide membrane surface chemistry affect gypsum scaling behavior, independent of membrane surface roughness. Our motivation is improving the scaling resistance of TFC desalination membranes through changes to the surface chemistry of the polyamide selective layer achieved simply through changing the terminating monomer of the mLbL polyamide. The $\mathrm{mLbL}$ deposition process introduces the prospect of tuning desalination membrane surface chemistry to address fouling and scaling challenges specific to different source waters, and our work advances the use of mLbL polyamide deposition to create and study model TFC membranes under desalination conditions.

\section{Experimental}

\subsection{Materials}

For preparation of polyamide films, $m$-phenylenediamine (MPD) and 1,3,5-benzenetricarbonyl trichloride (trimesoyl chloride, TMC) were purchased from Sigma-Aldrich and used as received. 
Acetone (ACS reagent grade, J.T. Baker) and toluene (ACS reagent grade, Taylor Scientific) were stored on aluminosilicate sieves (Type 4A, Fisher Chemical) and alumina (Acros Organics), respectively, to remove water before use. Films were deposited on silicon wafers (University Wafer, Boston, MA), silicon dioxide-coated quartz crystal microbalance sensors (QSense Inc., Biolin Scientific, Linthicum Heights, MD), and anodic aluminum oxide membranes (47 $\mathrm{mm}$ diameter, $0.02 \mu \mathrm{m}$ pore diameter, $60 \mu \mathrm{m}$ thickness, GE Healthcare Life Sciences). Poly(ethyleneimine) (PEI, $\mathrm{M}_{\mathrm{w}} \sim 750,000,50 \mathrm{wt} \%$ in water, Sigma-Aldrich), poly(acrylic acid) (PAA, $\mathrm{M}_{\mathrm{w}}>$ 200,000, $25 \mathrm{wt} \%$ in water, Polysciences, Inc.), sodium chloride (NaCl, J.T. Baker), calcium sulfate dihydrate $\left(\mathrm{CaSO}_{4} \cdot 2 \mathrm{H}_{2} \mathrm{O}\right.$, Sigma-Aldrich), calcium chloride dihydrate $\left(\mathrm{CaCl}_{2} \cdot 2 \mathrm{H}_{2} \mathrm{O}\right.$, Fisher Scientific), and sodium sulfate $\left(\mathrm{Na}_{2} \mathrm{SO}_{4}\right.$, Sigma-Aldrich) were used as received. Deionized (DI) water $(18.1 \mathrm{M} \Omega \mathrm{cm}$ ) was prepared in a Barnstead Nanopure system (Thermo Scientific).

\subsection{Polyamide films created by molecular layer-by-layer ( $m L b L)$ deposition}

The molecular layer-by-layer (mLbL) deposition process comprises alternating deposition cycles of different monomer solutions followed by solvent rinses. Each deposited monomer solution reacts with the pendant functional groups of the previously deposited monomer to build up molecular layers [23]. The technique has been demonstrated for thin polyamide films and was subsequently used to create TFC membranes with tunable water and salt permeabilities using porous polymer supports [24]. mLbL deposition enables polyamide selective layer properties to be tuned through changes in monomer chemistry [25], and our recent work has focused on the effect of terminating monomer on the surface properties of mLbL polyamide films [26].

Polyamide films with different surface chemistry were formed using a spin-assisted $\mathrm{mLbL}$ deposition technique [27]. TMC monomer solution (1 wt\% in toluene), toluene rinse, MPD monomer solution ( $1 \mathrm{wt} \%$ in toluene), and acetone rinse were sequentially deposited on silicon wafers or silicon dioxide-coated quartz crystal microbalance sensors. These deposition steps were repeated for 20 or 20.5 cycles, representing 40 and 41 monomer deposition steps, respectively. 20-cycle polyamide films were terminated in MPD monomer, and 20.5-cycle films were terminated in TMC monomer. Prior to $\mathrm{mLbL}$ polyamide deposition, substrates were 
cleaned for 10 minutes in a UV/ozone cleaner (Jelight Co., Irvine, CA), and following deposition, the films were annealed at $215^{\circ} \mathrm{C}$ for 1 minute. Terminating the polyamide films in MPD monomer solution resulted in surfaces that were enriched by unreacted amine functional groups. The surfaces of TMC-terminated polyamide films were enriched in carboxyl functional groups resulting from hydrolysis of unreacted acyl chloride groups [26].

\subsection{Polyamide thin-film composite (TFC) membranes created by $m L b L$ deposition}

Thin-film composite (TFC) membranes with different surface chemistries were created by spinassisted mLbL deposition [27] of 60-cycle MPD-terminated polyamide or 60.5-cyle TMCterminated polyamide films onto anodic aluminum oxide (AAO) membrane supports. Prior to mLbL polyamide deposition, the AAO membranes were cleaned for 10 minutes in a UV/ozone cleaner. Then, a polyelectrolyte bilayer was formed on the AAO membrane surface by sequential deposition of PEI solution (0.1 wt\% in water) and PAA solution ( $0.1 \mathrm{wt} \%$ in water) to prevent polyamide formation inside the AAO membrane pores during the subsequent $\mathrm{mLbL}$ polyamide deposition [24].

\subsection{Gypsum scaling solutions}

The scaling behavior of the polyamide films and membranes was evaluated with calcium sulfate dihydrate (gypsum, $\mathrm{CaSO}_{4} \cdot 2 \mathrm{H}_{2} \mathrm{O}$ ) solutions at a supersaturation index of 1.3 , which were prepared from $48 \mathrm{mM} \mathrm{Na}_{2} \mathrm{SO}_{4}$ and $48 \mathrm{mM} \mathrm{CaCl}_{2}$ precursor solutions, as determined using OLI Analyzer electrolyte modeling software (version 9.0, OLI Systems, Inc.). Gypsum supersaturation index, $S I_{g}$, is defined as

$$
S I_{g}=\frac{\left\{\mathrm{Ca}^{2+}\right\}\left\{\mathrm{SO}_{4}{ }^{2-}\right\}}{K_{S p}}
$$

where $K_{s p}$ is the gypsum solubility product constant, and $\left\{\mathrm{Ca}^{2+}\right\}\left\{\mathrm{SO}_{4}{ }^{2-}\right\}$ is the ion activity product [2]. 
The gypsum solutions had pH 5.3 as prepared, and pH was adjusted to 4, 7.5, and 10 where noted using concentrated $\mathrm{HCl}$ and $\mathrm{NaOH}$ solutions.

\subsection{Polyamide TFC membrane characterization}

The water permeability coefficient $\left(A, \mathrm{~L} \mathrm{~m}^{-2} \mathrm{~h}^{-1} \mathrm{bar}^{-1}\right)$ and solute permeability coefficient $(B, \mathrm{~L}$ $\mathrm{m}^{-2} \mathrm{~h}^{-1}$ ) of the polyamide and AAO composite membranes were determined from forward osmosis permeation experiments in a custom designed test cell using $\mathrm{NaCl}$ draw solution. The height of the feed and draw solution channels in the test cell was $0.4 \mathrm{~cm}$ each, and the active membrane area for permeation was $2.77 \mathrm{~cm}^{2}$. Using an established protocol [28], experimental forward osmosis flux data were fit to the standard film model that describes forward osmosis permeation to determine $A$ and $B$ coefficients. In the data fitting, a fixed structural parameter was calculated from the AAO membrane properties, as described in Section A.1 of Appendix A. Peristaltic pumps (Masterflex L/S, Cole-Parmer) were used to deliver feed and draw solutions at flowrates of $2 \mathrm{~mL} \mathrm{~min}^{-1}$, resulting in a cross flow velocity of $0.1 \mathrm{~cm} \mathrm{~s}^{-1}$ and laminar flow conditions within the test cell. A mass transfer coefficient for the feed solution channel was estimated from a Sherwood correlation for laminar flow [29].

\subsection{Gypsum scaling solution characterization}

The formation of gypsum crystals from a supersaturated gypsum solution $\left(S I_{g}=1.3, \mathrm{pH} 7.5\right)$ was monitored by dynamic light scattering, which was performed at a fixed angle $\theta=90$ degrees using a CGS-5000F goniometer (ALV GmbH, Langen, Germany) with an incident light of wavelength $\lambda=532 \mathrm{~nm}$ (coherent). The gypsum solution was mixed immediately before beginning measurements, and data were collected at 0, 100, 200, 250, and 350 minutes. The autocorrelated intensities were analyzed using the CONTIN algorithm to obtain relaxation time distributions [30]. The scattering vector is defined in Eq. A.2 of Appendix A.

The surface charge of the gypsum crystals was characterized from zeta potential measurements, which were obtained by electrophoretic light scattering using a Brookhaven NanoBrook Omni (Brookhaven Instruments Corporation), operating at a wavelength $\lambda=658 \mathrm{~nm}$. Five 
measurements per sample were collected for supersaturated gypsum solutions $\left(S I_{g}=1.3\right)$ at $\mathrm{pH} 4$, 7.5, and 10. Zeta potential values were calculated using the Smoluchowski equation.

\subsection{Microscopy and image analysis of scaled polyamide surfaces}

Images of the polyamide surfaces before and after gypsum scaling experiments were captured at $5 \mathrm{X}$ resolution with an optical microscope (Nikon Optiphot-2, Nikon Instruments, Inc.) equipped with a digital camera (ORCA-ER, Hamamatsu Photonics). Image processing to determine extent of surface coverage by gypsum was performed with an area analysis routine from Image $\mathbf{J}$ software (release 1.46, imagej.nih.gov).

\subsection{Quartz crystal microbalance (QCM) measurements of scaling kinetics}

Gypsum scaling kinetics for the TMC- and MPD-terminated polyamide films were studied using a quartz crystal microbalance (QCM, E-4 model, Q-Sense Inc., Biolin Scientific, Linthicum Heights, MD), which measures changes in the resonance frequency of a QCM sensor over time as it is exposed to a gypsum scaling solution. The changes in frequency $(\Delta f)$ at the third overtone were related to accumulated gypsum mass $(\Delta m)$ on the sensor via the Sauerbrey relationship [31]:

$$
\Delta m=-C \frac{1}{n} \Delta f
$$

where $C=17.7 \mathrm{ng} \mathrm{cm}^{-2} \mathrm{~s}^{-1}$ for AT-cut quartz QCM sensor, and $n$ is the overtone of fundamental resonance frequency $(n=3)$.

For QCM gypsum scaling kinetics experiments, 20-cycle MPD- and 20.5-cycle TMC-terminated polyamide films were deposited directly onto silicon dioxide-coated QCM sensors and were tested in parallel, exposed to the same feed solution and other experimental conditions. Kinetics of homogeneous nucleation and bulk deposition of gypsum scalant were observed by mixing the gypsum scaling solution $\left(S I_{g}=1.3\right)$ at the beginning of the experiment and pumping the solution at a flowrate of $0.50 \mathrm{~mL} \mathrm{~min}^{-1}$ across each QCM sensor using a peristaltic pump (Ismatec, IDEX 
Corporation). Heterogeneous nucleation and surface crystallization of gypsum scalant were observed by mixing $\mathrm{CaCl}_{2}$ and $\mathrm{Na}_{2} \mathrm{SO}_{4}$ precursor solutions at flowrates of $0.25 \mathrm{~mL} \mathrm{~min}^{-1}$ with an inline static mixer immediately upstream of the QCM sensors. The mixed gypsum scaling solution $\left(S I_{g}=1.3\right.$ ) was filtered through a $0.45 \mu \mathrm{m}$ syringe filter (Advantec MFS, Inc.) to remove any suspended particles before flowing across each QCM sensor at $0.50 \mathrm{~mL} \mathrm{~min}^{-1}$.

\subsection{Forward osmosis dynamic tests for polyamide TFC membrane scaling}

The gypsum scaling behavior of thin-film composite membranes with 60-cycle MPD- and 60.5cycle TMC-terminated polyamide selective layers was studied through forward osmosis crossflow tests. Permeate flux was measured over time as the membranes were exposed to supersaturated gypsum feed solution $\left(S I_{g}=1.3\right)$. Dynamic scaling tests were conducted without solution recycling such that feed and draw solutions made a single pass through the membrane test cells. Permeate flux was calculated from the changes in mass of the feed and draw solutions over time. Permeation tests were conducted at feed solution and draw solution cross flow velocities of $0.1 \mathrm{~cm} \mathrm{~s}^{-1}$ using the same tests cells as were used for membrane characterization.

For the forward osmosis scaling tests, heterogeneous gypsum nucleation and surface crystallization behavior was targeted by mixing $\mathrm{CaCl}_{2}$ and $\mathrm{Na}_{2} \mathrm{SO}_{4}$ precursor solutions inline with a static mixer to form a supersaturated gypsum feed solution $\left(S I_{g}=1.3\right)$ that was then filtered to remove suspended particles. $\mathrm{NaCl}$ was the draw solute, and the draw solution concentration for each membrane sample was selected to target an initial permeate flux of $10 \mathrm{~L} \mathrm{~m}^{-2} \mathrm{~h}^{-1}$ that would result in a feed solution concentrative external concentration polarization factor of 2.2 at the polyamide selective layer. Permeate fluxes and concentration polarization factors were estimated from the standard thin-film model for forward osmosis permeation [28]. Dynamic scaling tests for TMC- and MPD-terminated polyamide membranes were conducted in parallel so that the membranes were subjected to the same experimental conditions. 


\section{Results and Discussion}

\subsection{Polyamide film characteristics}

Polyamide thin films formed by the spin-assisted mLbL technique were extensively characterized in our recent work [26]. The surface roughness of these films was observed to be $\sim 1 \mathrm{~nm}$, which is two orders of magnitude less than conventional interfacially-polymerized polyamide membranes $[32,33]$. Buffered water contact angle measurements and negative charge density measurements, both of which probe the near-surface region, were similar for the MPDand TMC-terminated polyamide films. These two measurements indicate that, despite their distinct surface chemistries, the polyamide films have the same near-surface ionization behavior due to the presence of carboxyl groups in the near-surface region. X-ray photoelectron spectroscopy measurements and atomic force microscopy measurements of adhesion force confirmed the unique amine-enriched and carboxyl-enriched surface chemistries of the MPDand TMC-terminated polyamide films, respectively [26]. The different surface chemistry but identical roughness and charge density of the mLbL polyamide films enables the effects of different polyamide surface chemistry on scaling propensity to be investigated independently of other surface properties.

\subsection{Polyamide TFC membrane transport properties}

Composite membranes fabricated with MPD- and TMC-terminated polyamide exhibit water $(A)$ and solute $(B)$ permeability coefficients similar to those of interfacially-polymerized TFC membranes that were characterized using the same technique [28], as illustrated in Fig. 1 and summarized in Table A.1 of Appendix A. Ratios of $A / B$, a measure of membrane selectivity, range from 3 to $10 \mathrm{bar}^{-1}$ and from 3 to $7 \mathrm{bar}^{-1}$ for the mLbL polyamide and interfaciallypolymerized polyamide membranes, respectively. The similar transport properties demonstrate the suitability of the mLbL polyamide membranes as model materials for conventional interfacially-polymerized polyamide membranes. The mLbL membranes can achieve smooth polyamide selective layers with different surface chemistry while maintaining similar transport behavior to conventional desalination membranes. 


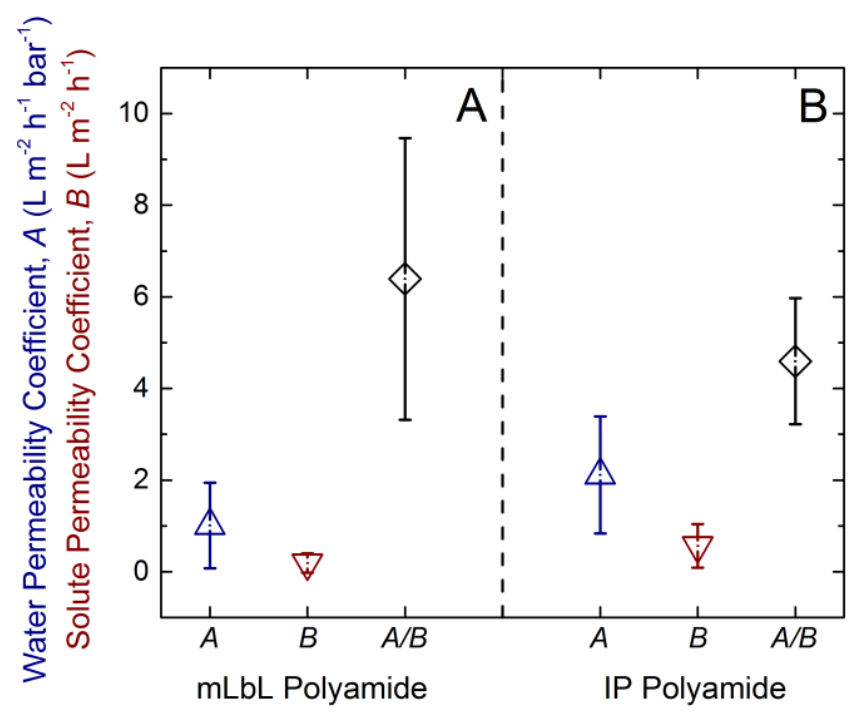

Figure 1. Comparison of water permeability coefficients $\left(A, \mathrm{~L} \mathrm{~m}^{-2} \mathrm{~h}^{-1} \mathrm{bar}^{-1}\right)$, solute permeability coefficients $\left(B, \mathrm{~L} \mathrm{~m}^{-2} \mathrm{~h}^{-1}\right)$, and $A / B$ ratios $\left(\right.$ bar $\left.^{-1}\right)$ for $\left.\mathrm{A}\right)$ the thin-film composite membranes formed by molecular layer-by-layer (mLbL) deposition of polyamide on anodic aluminum oxide membrane supports described in this work and for B) thin-film composite membranes formed by interfacial polymerization (IP) of polyamide described by Tiraferri et al [28]. The $A / B$ ratio of water and solute permeability coefficients is a measure of membrane selectivity. Symbols represent the mean value of 5 samples of mLbL polyamide membranes and 9 samples of IP polyamide membranes. Error bars extend to one standard deviation.

\subsection{Gypsum scaling solution characteristics}

Light scattering measurements show that the gypsum scaling solution $\left(S I_{g}=1.3, \mathrm{pH} 7.5\right)$ homogeneously nucleates, and crystals grow in size from a hydrodynamic radius of $0.03 \mu \mathrm{m}$ to $0.27 \mu \mathrm{m}$ within 200 minutes of mixing the solution. A summary of dynamic light scattering results is included in Table A. 2 of Appendix A. Calculated zeta potentials were negative for supersaturated gypsum solutions at $\mathrm{pH} 4,7.5$, and 10, indicating a negative surface charge for the gypsum crystals, as summarized in Fig. A.1 and Table A.3 of Appendix A. This result is 
consistent with previous determinations of negative zeta potential for gypsum suspensions across the $\mathrm{pH}$ range 3-10 [34, 35].

\subsection{Gypsum scaling of polyamide films by homogenous nucleation and bulk deposition}

QCM experiments performed under conditions of gypsum homogeneous nucleation and bulk deposition (described in Section 2.8) illustrate similar long-term scaling behavior for MPD- and TMC- terminated polyamide films under all $\mathrm{pH}$ conditions investigated (Fig. 2). As shown, the total deposited gypsum mass after 100 minutes was equivalent for the different polyamide films, and the deposited mass generally increased with increasing gypsum solution $\mathrm{pH}$.

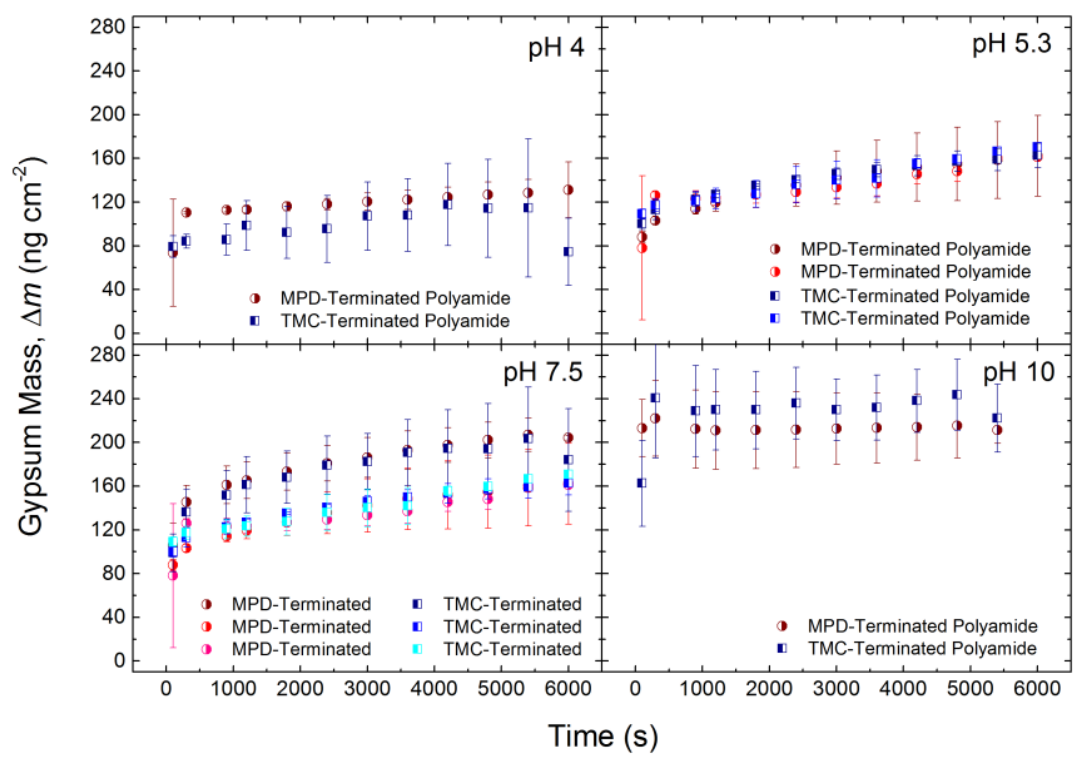

Figure 2. Accumulated gypsum masses, $\Delta m\left(\mathrm{ng} \mathrm{cm}^{-2}\right)$, on $m$-phenylene diamine (MPD) and trimesoyl chloride (TMC) terminated polyamide films during quartz crystal microbalance experiments conducted with a supersaturated gypsum solution (supersaturation index $=1.3$ ) under conditions of homogeneous nucleation and bulk gypsum deposition. Plots show results from scaling experiments performed at gypsum feed solution $\mathrm{pH}$ of $4,5.3,7.5$, and 10 , as indicated in upper right corner of each panel. Circular symbols with solid right half indicate the mean value of gypsum mass accumulation on MPD-terminated polyamide films, and square symbols with solid left half indicate mean values for TMC-terminated polyamide films. Each set 
of symbols represents the mean values of a minimum of three measurements on a single sample, and error bars extend to one standard deviation.

Though long-term bulk deposition of gypsum is similar for the MPD- and TMC-terminated polyamide films, the initial gypsum bulk deposition flux is influenced by polyamide surface chemistry. For both MPD- and TMC-terminated films, a rapid increase in deposited gypsum mass occurs within the initial $180 \mathrm{~s}$ of the QCM experiments, as shown in the representative plots in Fig. 3A. At high and low gypsum solution $\mathrm{pH}$, the initial gypsum deposition flux is higher for MPD-terminated polyamide films. Fig. 3B compares the initial gypsum deposition fluxes observed for the differently-terminated polyamide films at different gypsum solution $\mathrm{pH}$. The flux was determined by a linear fit to $60 \mathrm{~s}$ of QCM data representing the rapid mass deposition that occurs within the initial $180 \mathrm{~s}$ of each experiment. In Fig. 3B, the initial deposition fluxes at each $\mathrm{pH}$ value are normalized to the fluxes observed for the TMC-terminated polyamide films.
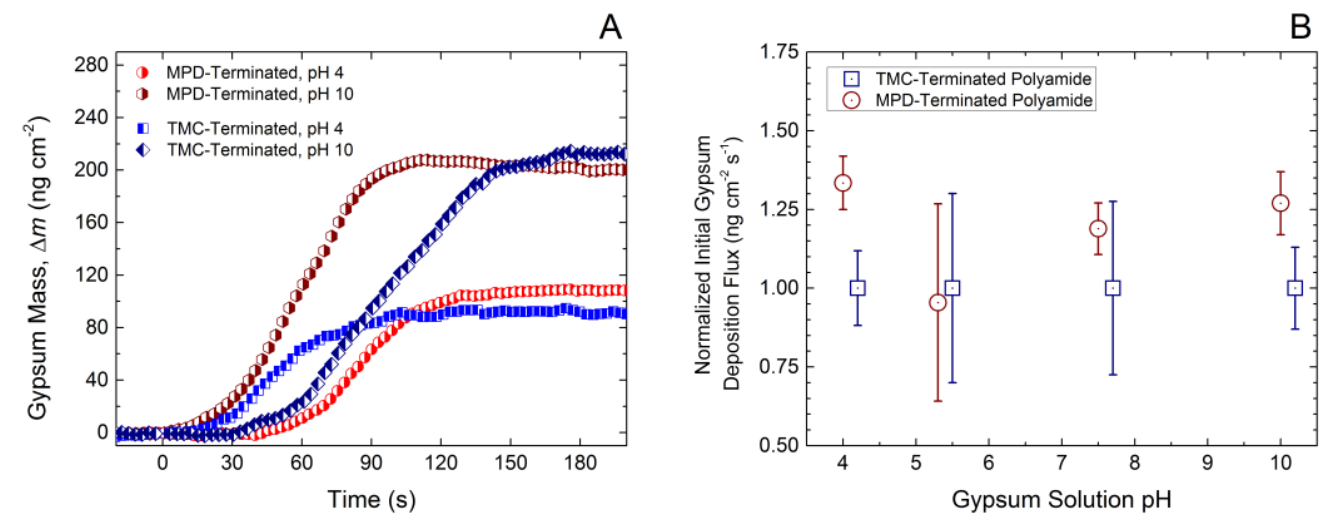

Figure 3. Initial gypsum deposition fluxes from homogeneous nucleation and bulk deposition scaling experiments with a supersaturated gypsum solution (supersaturation index $=1.3$ ). A) Representative mass deposition data from quartz crystal microbalance experiments, $\Delta m\left(\mathrm{ng} \mathrm{cm}^{-}\right.$ ${ }^{2}$ ), show a rapid gypsum deposition flux within the initial $180 \mathrm{~s}$ of the experiment. B) Comparison of initial gypsum mass deposition fluxes $\left(\mathrm{ng} \mathrm{cm}^{-2} \mathrm{~s}^{-1}\right)$ for $m$-phenylene diamine (MPD) and trimesoyl chloride (TMC) terminated polyamide films at different gypsum solution 
$\mathrm{pH}$. The mean fluxes for MPD- and TMC-terminated polyamide are represented by circular and square symbols, respectively, and were normalized to the values for TMC-terminated polyamide. Symbols represent the mean values of a minimum of three measurements for each polyamide films type at each gypsum solution $\mathrm{pH}$. Error bars extend to one standard deviation.

For gypsum solutions at $\mathrm{pH} 4$ and 10, the initial gypsum deposition flux is significantly greater for MPD-terminated polyamide films compared to TMC-terminated polyamide, as determined by a two-sided t-test at significance level $\alpha=0.05$. However, at gypsum solution pH 5.3 and 7.5, the initial deposition fluxes are not significantly different. The differences in initial gypsum deposition flux at different gypsum solution $\mathrm{pH}$ can be explained by the dissociation constants for the carboxyl and amine functional groups on and near the surface of the polyamide films. Effective dissociation constants, $\mathrm{pK}_{\mathrm{a}}{ }^{\mathrm{eff}}$, for carboxyl groups in polyamide have been reported in the $\mathrm{pH}$ range 4-9 [36-38] and for amine groups in polyamide in the $\mathrm{pH}$ range 4-11 [36, 37]. At high $\mathrm{pH}(\geq 9)$, when the polyamide films are more negatively charged because of deprotonated carboxylic acid groups and uncharged amine groups, the negatively-charged gypsum particles deposit more rapidly on the less negatively charged MPD-terminated polyamide films, which have more uncharged surface amine groups. At low $\mathrm{pH}(\leq 4)$, when the films are more positively charged because of protonated amine groups and uncharged carboxylic acid groups, the negatively-charged gypsum particles deposit more rapidly on the more positively charged MPD-terminated films.

At intermediate $\mathrm{pH}(4<\mathrm{pH}<9)$, the polyamide films are expected to have mixed surface charges from deprotonated carboxyl groups and protonated amine groups, and there is no significant difference in the initial gypsum deposition fluxes. Measurements of buffered contact angles on the polyamide films support the occurrence of mixed surface charges at intermediate $\mathrm{pH}$. The ionization fractions of MPD- and TMC-terminated polyamide, calculated from buffered contact angle measurements, indicate a transition region from $\mathrm{pH} 6$ to 8 [26]. In this region, carboxyl groups on the surface of TMC-terminated polyamide films transition from a protonated and uncharged state to a deprotonated and negatively charged state. MPD-terminated polyamide 
films exhibit a plateau at 50\% ionization fraction, indicating simultaneous deprotonation of positively charged amine groups and uncharged carboxyl groups.

The difference between initial and long-term bulk deposition scaling behavior may be attributed to the effect of polyamide film conditioning. After the initial rapid deposition of gypsum crystals from the bulk solution, which is influenced by polyamide surface chemistry, the surfaces of the polyamide films become conditioned with gypsum, and differences in surface chemistry are no longer apparent. Subsequently deposited gypsum crystals interact with the gypsum conditioning layer instead of the polyamide surface. The effect of membrane surface properties on initial, but not long-term, fouling behavior has also been observed for organic foulants, where the membrane surface becomes conditioned with adsorbed foulants over time [3].

\subsection{Gypsum scaling of polyamide films by heterogeneous nucleation and surface crystallization.}

QCM surface crystallization experiments represented conditions of isothermal surface nucleation at constant saturation (described in Section 2.8). For these conditions, a plot of the logarithm of the cumulative probability that nucleation has not occurred provides information about the nucleation kinetics [39]. QCM mass accumulation data $(\Delta m)$ were related to scaling probability using the area of the polyamide-coated QCM sensor surfaces covered by gypsum scale. The probability that scaling had not occurred was represented as the percent area of the polyamide film not covered by gypsum scale, which was determined from observations of the percent area covered by gypsum scale at the end of each 50-h QCM surface crystallization experiment (\% area scaled $(50 \mathrm{~h})$ ). The total gypsum mass accumulated at end of the experiment for each polyamide film $(\Delta m(50 h))$ was assigned the corresponding percent area of gypsum coverage observed for that film. Previous work studying gypsum scaling of polymeric surfaces has shown a correlation between percent area of scaling coverage and the mass accumulation observed by QCM [17].

The probability that nucleation occurred over time during the QCM experiments was taken as the fraction of the total gypsum mass accumulation over time $(\Delta m(t) / \Delta m(50 h))$ multiplied by the percent area of gypsum coverage observed at the end of the experiment. The probability that 
nucleation had not occurred, $P(t)$, was calculated as $100 \%$ minus the probability that nucleation had occurred:

$$
P(t)=100 \%-\left(\frac{\Delta m(t)}{\Delta m(50 h)}\right)(\% \text { area scaled }(50 h))
$$

Each pair of TMC- and MPD-terminated polyamide films that was tested in parallel demonstrated a similar degree of gypsum scaling, as measured by surface coverage at the end of the experiment. Though scaling behavior was similar for both films in each of the three different QCM experiments, the percent area of the films covered by gypsum scale after $50 \mathrm{~h}$ ranged by orders of magnitude between the different experiments, as shown in Fig. 4A. Plots of the natural logarithm of the probability that nucleation had not occurred, $\ln (P(t))$, are linear, indicating a constant gypsum nucleation rate [39], as shown in Fig. 4B. These results suggest that differences in polyamide surface chemistry do not significantly affect gypsum surface crystallization under these conditions.
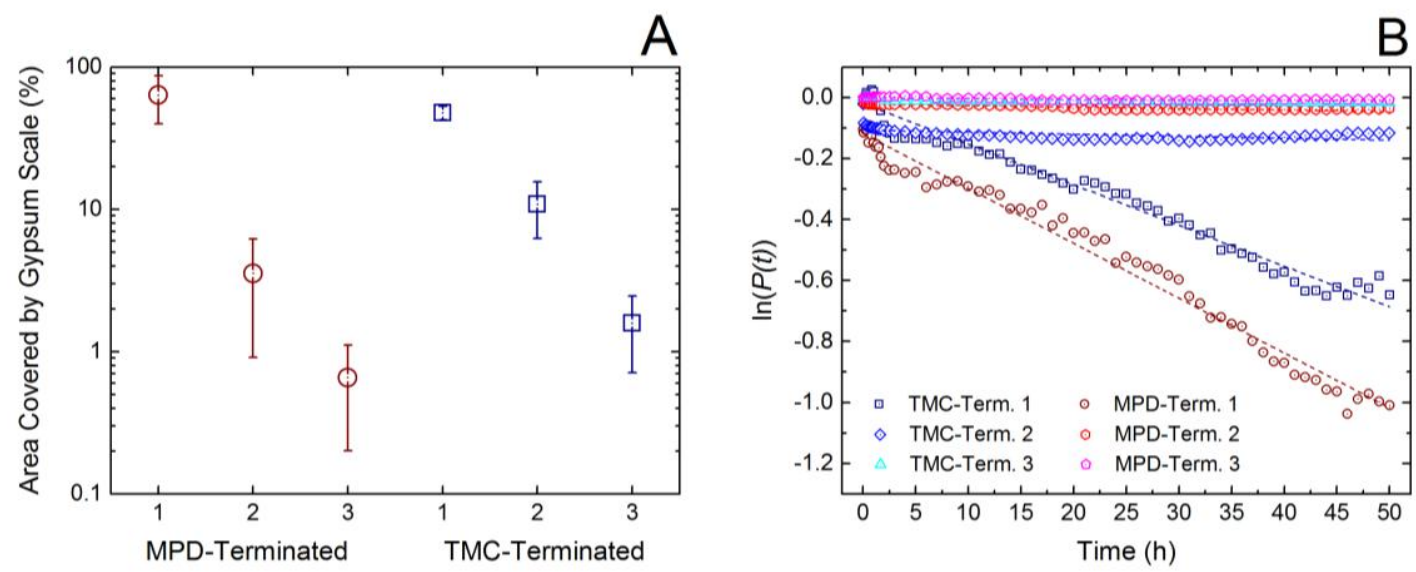

Figure 4. Results from heterogeneous nucleation and gypsum surface crystallization experiments. A) Comparison of the percent area covered by gypsum scale (logarithmic scale) for $m$-phenylene diamine (MPD) and trimesoyl chloride (TMC) terminated polyamide films. The polyamide films were deposited on quartz crystal microbalance sensors and exposed to supersaturated gypsum solution (supersaturation index $=1.3$ ) for $50 \mathrm{~h}$. Mean values of percent 
area covered by gypsum scale for MPD- and TMC-terminated polyamide films are represented by circular and square symbols, respectively. Error bars extend to one standard deviation for the six measurements made on each sample. Sample numbers on the horizontal axis correspond to MPD- and TMC-terminated films that were tested in parallel. B) Plots of the natural logarithm of the cumulative probability that scaling has not occurred $(\ln (P(t)))$ from quartz crystal microbalance experiments with TMC- and MPD-terminated polyamide films. Symbols represent probabilities that scaling has not occurred over time, which were determined from mass accumulation data and gypsum area coverage on the films. Dashed lines represent linear fits to the data. Sample numbers in the legend correspond to TMC- and MPD-terminated films that were tested in parallel and also correspond to the sample numbers in Fig. 4A.

\subsection{Gypsum scaling of polyamide TFC membranes during forward osmosis dynamic tests}

Forward osmosis dynamic scaling tests conducted under conditions of heterogeneous nucleation and surface crystallization resulted in gypsum scaling for both the MPD- and TMC-terminated polyamide membranes. Membrane permeate water fluxes, $J_{w}\left(\mathrm{~L} \mathrm{~m}^{-2} \mathrm{~h}^{-1}\right)$, during the $30-\mathrm{h}$ experiment are shown in Fig. 5A. The moving averages of 3 hourly flux measurements are presented, with the standard deviations serving as a measure of experimental error. Fig. 5B includes images of the MPD- and TMC-terminated polyamide membrane selective layers at the conclusion of the forward osmosis scaling test. The presence of gypsum rosettes confirms scaling by heterogeneous nucleation [40]. 

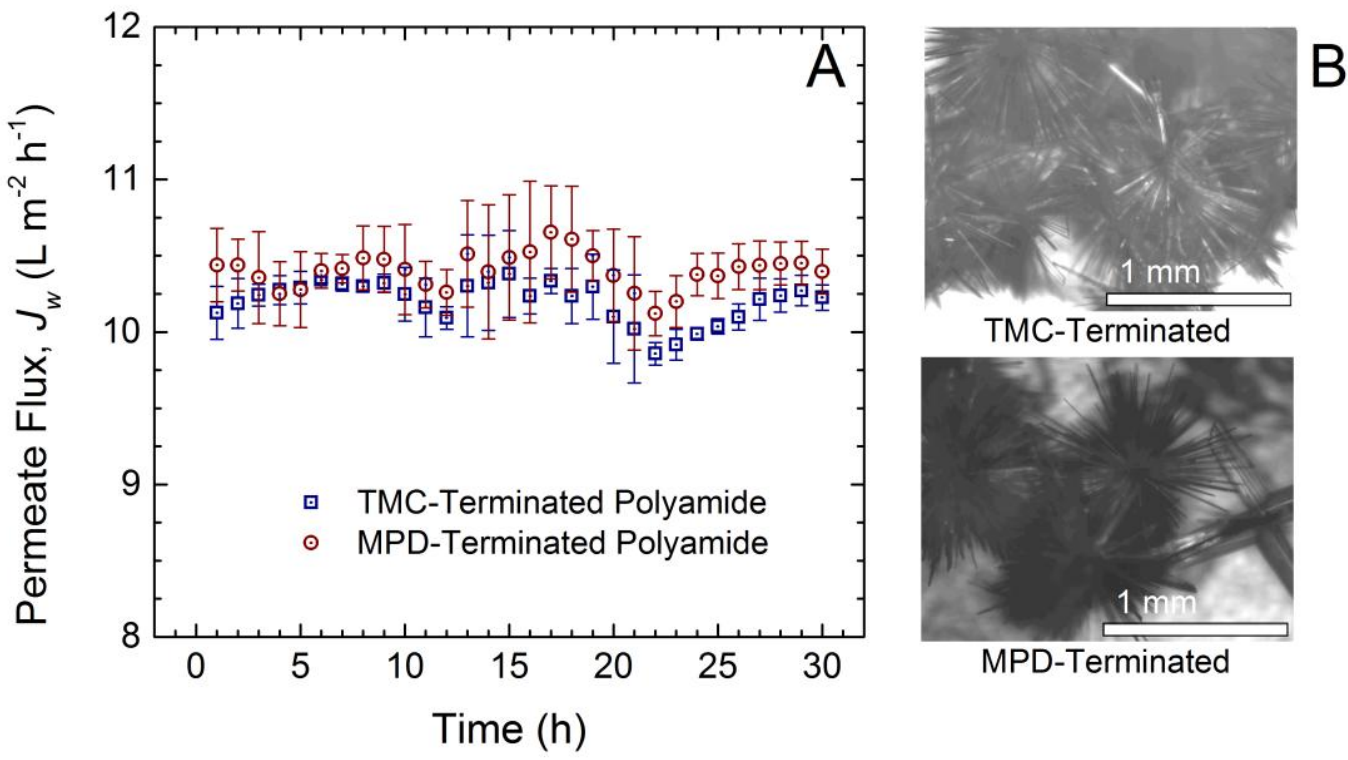

Figure 5. A) Permeate water flux $\left(J_{w}, \mathrm{~L} \mathrm{~m}^{-2} \mathrm{~h}^{-1}\right)$ for trimesoyl chloride (TMC) and $m$-phenylene diamine (MPD) terminated polyamide thin-film composite membranes exposed to gypsum solution at a supersaturation index of 1.3 during a $30 \mathrm{~h}$ forward osmosis dynamic scaling test. Membranes were tested in parallel. Permeate water fluxes for TMC-terminated membranes and MPD-terminated membranes are represented by square and circle symbols, respectively. Symbols represent the moving average value of three hourly flux measurements. Error bars extend to one standard deviation. B) Images of the polyamide selective layer of MPD- and TMCterminated thin-film composite membranes at the conclusion of the $30 \mathrm{~h}$ forward osmosis permeation test. Scale bars are $1 \mathrm{~mm}$. Gypsum scaling by surface crystallization is apparent by the presence of gypsum rosettes on the polyamide membrane surfaces.

Significant declines in permeate water fluxes were not observed during the forward osmosis test, even though gypsum surface crystallization was evident on both membranes. A decline in flux is expected for the scaled membranes as nucleated gypsum crystals grow and block the membrane surface, reducing area for permeation [41]. The lack of observable flux decline may reflect a different morphology of gypsum scale resulting from the different hydrodynamic conditions and lower crossflow velocity used in this forward osmosis experiment compared to previously reported membrane flux decline tests with gypsum [14, 40, 42]. 
At the conclusion of the forward osmosis dynamic test, the gypsum scale covering the MPD- and TMC-terminated membranes appeared as a loose structure of white crystals that spanned the entire membrane active area. Differences in the density and structure of gypsum scale have been observed in reverse osmosis flux decline experiments using different polyamide TFC membranes and at different gypsum supersaturation indices [40], and have also been observed in forward osmosis flux decline experiments using different membrane materials [14]. In the reverse osmosis experiments, flux decline did not correlate exactly with membrane surface area coverage by gypsum scale, indicating that permeation occurs through spaces in and around nucleated gypsum rosettes [42]. Similarly, in forward osmosis experiments, relatively little permeate flux decline was observed for a cellulose acetate membrane compared to a polyamide TFC membrane, though gypsum scaling occurred on both membrane surfaces [14]. For our forward osmosis test of MPD- and TMC-terminated polyamide membranes, we conclude that the loose, open structure of the gypsum crystals did not block the surface area of the membranes to the extent that the scaling caused any significant flux decline.

The low-density structure of gypsum scale observed for these forward osmosis scaling test is consistent with the general characteristics of membrane fouling layers in forward osmosis compared to those formed in pressurized membrane desalination systems. Studies of membrane fouling during reverse osmosis and forward osmosis by organic macromolecules [43] and biofilms [44] have demonstrated that foulant layers have a more dense structure and cause greater permeate flux decline under reverse osmosis conditions compared to forward osmosis. Similar to the permeation test results presented in Fig. 5, researchers have also observed the accumulation of thick loosely-structured foulant layers of alginate [45] and humic acid [46] on the membrane surface during forward osmosis desalination with no corresponding declines in permeate fluxes.

Although permeate fluxes were relatively low during the dynamic scaling test $\left(J_{w} \sim 10 \mathrm{~L} \mathrm{~m}^{-2} \mathrm{~h}^{-1}\right)$, extensive gypsum surface crystallization was observed as a result of the concentrative external concentration polarization at the membrane surface under the laminar flow conditions of the test. Concentrative external concentration polarization factors were calculated, and forward osmosis 
permeation test conditions are summarized in Section A.5 and Table A.4 of Appendix A. Concentrative external concentration polarization is a function of permeate flux (Eq. A.3), and thus, the concept of a "critical flux" for mineral scaling is reflected in the concentrative external concentration polarization factor. The influence of concentration polarization and critical flux on membrane fouling and scaling has been well-documented $[3,10]$, and the results of the forward osmosis dynamic scaling test suggests that these hydrodynamic conditions have a greater effect than differences in surface chemistry on the gypsum scaling behavior of polyamide TFC membranes.

\section{Conclusions}

In this work, we demonstrate mLbL deposition of polyamide as a valuable tool for studying the polyamide selective layers of TFC desalination membranes. We investigated the influence of differences in polyamide surface chemistry on gypsum scaling, independent of the effects of surface roughness, by fabricating smooth films with tunable MPD- or TMC-terminated surface chemistry. Composite membranes fabricated by mLbL polyamide deposition exhibited transport properties similar to conventional interfacially-polymerized membranes. Experimental studies did not show an effect of different polyamide surface chemistry on long-term gypsum scaling propensity. In QCM experiments under identical long-term homogeneous or heterogeneous nucleation conditions, MPD- and TMC-terminated polyamide films behaved similarly, including similar accumulated gypsum masses, surface coverage by gypsum scale, and surface nucleation rates. Forward osmosis dynamic scaling tests also showed similar scaling behavior for MPD- and TMC-terminated polyamide membranes. Hydrodynamic conditions appear to play a significant role in the occurrence of gypsum scaling by surface crystallization and the morphology of the resultant scale. Our findings, considered in the context of previous gypsum scaling studies with rough heterogeneous polyamide TFC membranes, suggest that efforts to develop anti-scaling polyamide membranes should focus on the effects of membrane surface roughness and hydrodynamics rather than changes to MPD and TMC polyamide surface chemistry. 


\section{Acknowledgments}

We acknowledge a STAR Fellowship awarded by the US Environmental Protection Agency to

D.L.S. and a Graduate Research Fellowship awarded by the US National Science Foundation to M.E.T. Facilities use was supported by YINQE and NSF MRSEC DMR 1119826. Dynamic light scattering and zeta potential measurements were conducted in the Facility for Light Scattering at Yale University. We thank the Materials Science and Engineering Division at the National Institute of Standards and Technology for the use of the spin-assisted molecular layerby-layer deposition apparatus and the quartz crystal microbalance. 


\section{References}

[1] S. Lee, J. Cho, M. Elimelech, Influence of colloidal fouling and feed water recovery on salt rejection of RO and NF membranes, Desalination, 160 (2004) 1-12.

[2] A. Antony, J.H. Low, S. Gray, A.E. Childress, P. Le-Clech, G. Leslie, Scale formation and control in high pressure membrane water treatment systems: A review, Journal of Membrane Science, 383 (2011) 1-16.

[3] Q. She, R. Wang, A.G. Fane, C.Y. Tang, Membrane fouling in osmotically driven membrane processes: A review, Journal of Membrane Science, 499 (2016) 201-233.

[4] L.F. Greenlee, D.F. Lawler, B.D. Freeman, B. Marrot, P. Moulin, Reverse osmosis desalination: Water sources, technology, and today's challenges, Water Research, 43 (2009) 2317-2348.

[5] D.L. Shaffer, L.H. Arias Chavez, M. Ben-Sasson, S. Romero-Vargas Castrillón, N.Y. Yip, M. Elimelech, Desalination and Reuse of High-Salinity Shale Gas Produced Water: Drivers, Technologies, and Future Directions, Environmental Science \& Technology, 47 (2013) 95699583.

[6] Y.A. Le Gouellec, M. Elimelech, Calcium sulfate (gypsum) scaling in nanofiltration of agricultural drainage water, Journal of Membrane Science, 205 (2002) 279-291.

[7] Y.A. Le Gouellec, M. Elimelech, Control of calcium sulfate (gypsum) scale in nanofiltration of saline agricultural drainage water, Environmental engineering science, 19 (2002) 387-397.

[8] A. Rahardianto, B.C. McCool, Y. Cohen, Reverse Osmosis Desalting of Inland Brackish Water of High Gypsum Scaling Propensity: Kinetics and Mitigation of Membrane Mineral Scaling, Environmental Science \& Technology, 42 (2008) 4292-4297.

[9] B.R. Smith, F. Sweett, The crystallization of calcium sulfate dihydrate, Journal of Colloid and Interface Science, 37 (1971) 612-618.

[10] S. Shirazi, C.-J. Lin, D. Chen, Inorganic fouling of pressure-driven membrane processes A critical review, Desalination, 250 (2010) 236-248.

[11] M. Elimelech, W.A. Phillip, The Future of Seawater Desalination: Energy, Technology, and the Environment, Science, 333 (2011) 712-717.

[12] J.R. Werber, C.O. Osuji, M. Elimelech, Materials for next-generation desalination and water purification membranes, Nature Reviews Materials, 1 (2016) 16018.

[13] P. Xu, C. Bellona, J.E. Drewes, Fouling of nanofiltration and reverse osmosis membranes during municipal wastewater reclamation: Membrane autopsy results from pilot-scale investigations, Journal of Membrane Science, 353 (2010) 111-121. 
[14] B. Mi, M. Elimelech, Gypsum Scaling and Cleaning in Forward Osmosis: Measurements and Mechanisms, Environmental Science \& Technology, 44 (2010) 2022-2028.

[15] B. Mi, M. Elimelech, Silica scaling and scaling reversibility in forward osmosis, Desalination, 312 (2013) 75-81.

[16] N.H. Lin, M.-m. Kim, G.T. Lewis, Y. Cohen, Polymer surface nano-structuring of reverse osmosis membranes for fouling resistance and improved flux performance, Journal of Materials Chemistry, 20 (2010) 4642-4652.

[17] N.H. Lin, W.-Y. Shih, E. Lyster, Y. Cohen, Crystallization of calcium sulfate on polymeric surfaces, Journal of Colloid and Interface Science, 356 (2011) 790-797.

[18] N.H. Lin, Y. Cohen, QCM study of mineral surface crystallization on aromatic polyamide membrane surfaces, Journal of Membrane Science, 379 (2011) 426-433.

[19] V. Freger, Nanoscale Heterogeneity of Polyamide Membranes Formed by Interfacial Polymerization, Langmuir, 19 (2003) 4791-4797.

[20] Y. Liu, B. Mi, Effects of organic macromolecular conditioning on gypsum scaling of forward osmosis membranes, Journal of Membrane Science, 450 (2014) 153-161.

[21] S.C. Chen, J. Su, F.-J. Fu, B. Mi, T.-S. Chung, Gypsum (CaSO4· 2H2O) scaling on polybenzimidazole and cellulose acetate hollow fiber membranes under forward osmosis, Membranes, 3 (2013) 354-374.

[22] Z. Steiner, H. Rapaport, Y. Oren, R. Kasher, Effect of Surface-Exposed Chemical Groups on Calcium-Phosphate Mineralization in Water-Treatment Systems, Environmental Science \& Technology, 44 (2010) 7937-7943.

[23] P.M. Johnson, J. Yoon, J.Y. Kelly, J.A. Howarter, C.M. Stafford, Molecular layer-by-layer deposition of highly crosslinked polyamide films, Journal of Polymer Science Part B: Polymer Physics, 50 (2012) 168-173.

[24] J.-E. Gu, S. Lee, C.M. Stafford, J.S. Lee, W. Choi, B.-Y. Kim, K.-Y. Baek, E.P. Chan, J.Y. Chung, J. Bang, J.-H. Lee, Molecular Layer-by-Layer Assembled Thin-Film Composite Membranes for Water Desalination, Advanced Materials, 25 (2013) 4778-4782.

[25] W. Choi, J.-E. Gu, S.-H. Park, S. Kim, J. Bang, K.-Y. Baek, B. Park, J.S. Lee, E.P. Chan, J.H. Lee, Tailor-Made Polyamide Membranes for Water Desalination, ACS Nano, 9 (2015) 345355.

[26] M.E. Tousley, D.L. Shaffer, J.-H. Lee, C.O. Osuji, M. Elimelech, Effect of Terminating Molecule on Molecular Layer-by-Layer Polyamide Surface Properties, Langmuir, submitted (2016). 
[27] E.P. Chan, J.-H. Lee, J.Y. Chung, C.M. Stafford, An automated spin-assisted approach for molecular layer-by-layer assembly of crosslinked polymer thin films, Review of Scientific Instruments, 83 (2012) 114102.

[28] A. Tiraferri, N.Y. Yip, A.P. Straub, S. Romero-Vargas Castrillon, M. Elimelech, A method for the simultaneous determination of transport and structural parameters of forward osmosis membranes, Journal of Membrane Science, 444 (2013) 523-538.

[29] J.R. McCutcheon, M. Elimelech, Influence of concentrative and dilutive internal concentration polarization on flux behavior in forward osmosis, Journal of Membrane Science, 284 (2006) 237-247.

[30] S.W. Provencher, CONTIN: a general purpose constrained regularization program for inverting noisy linear algebraic and integral equations, Computer Physics Communications, 27 (1982) 229-242.

[31] L.T. Kearney, J.A. Howarter, QCM-Based Measurement of Chlorine-Induced Polymer Degradation Kinetics, Langmuir, 30 (2014) 8923-8930.

[32] A.K. Ghosh, B.-H. Jeong, X. Huang, E.M.V. Hoek, Impacts of reaction and curing conditions on polyamide composite reverse osmosis membrane properties, Journal of Membrane Science, 311 (2008) 34-45.

[33] A.K. Ghosh, E.M.V. Hoek, Impacts of support membrane structure and chemistry on polyamide-polysulfone interfacial composite membranes, Journal of Membrane Science, 336 (2009) 140-148.

[34] G.I. Dávila-Pulido, A. Uribe-Salas, Effect of calcium, sulphate and gypsum on copperactivated and non-activated sphalerite surface properties, Minerals Engineering, 55 (2014) 147153.

[35] B. Salopek, D. Krasić, S. Filipović, Measurement and application of zeta-potential, Rudarsko-geološko-naftni fakultet, 1992.

[36] C.C. Wamser, M.I. Gilbert, Detection of surface functional group asymmetry in interfacially-polymerized films by contact angle titrations, Langmuir, 8 (1992) 1608-1614.

[37] O. Coronell, B.J. Mariñas, X. Zhang, D.G. Cahill, Quantification of Functional Groups and Modeling of Their Ionization Behavior in the Active Layer of FT30 Reverse Osmosis Membrane, Environmental Science \& Technology, 42 (2008) 5260-5266.

[38] O. Coronell, B.J. Mariñas, D.G. Cahill, Depth Heterogeneity of Fully Aromatic Polyamide Active Layers in Reverse Osmosis and Nanofiltration Membranes, Environmental Science \& Technology, 45 (2011) 4513-4520. 
[39] R.P. Sear, Quantitative studies of crystal nucleation at constant supersaturation: experimental data and models, CrystEngComm, 16 (2014) 6506-6522.

[40] W.-Y. Shih, A. Rahardianto, R.-W. Lee, Y. Cohen, Morphometric characterization of calcium sulfate dihydrate (gypsum) scale on reverse osmosis membranes, Journal of Membrane Science, 252 (2005) 253-263.

[41] J. Gilron, D. Hasson, Calcium sulphate fouling of reverse osmosis membranes: Flux decline mechanism, Chemical Engineering Science, 42 (1987) 2351-2360.

[42] A. Rahardianto, W.-Y. Shih, R.-W. Lee, Y. Cohen, Diagnostic characterization of gypsum scale formation and control in RO membrane desalination of brackish water, Journal of Membrane Science, 279 (2006) 655-668.

[43] S. Lee, C. Boo, M. Elimelech, S. Hong, Comparison of fouling behavior in forward osmosis (FO) and reverse osmosis (RO), Journal of Membrane Science, 365 (2010) 34-39.

[44] S.E. Kwan, E. Bar-Zeev, M. Elimelech, Biofouling in forward osmosis and reverse osmosis: Measurements and mechanisms, Journal of Membrane Science, 493 (2015) 703-708.

[45] M. Xie, J. Lee, L.D. Nghiem, M. Elimelech, Role of pressure in organic fouling in forward osmosis and reverse osmosis, Journal of Membrane Science, 493 (2015) 748-754.

[46] M. Xie, L.D. Nghiem, W.E. Price, M. Elimelech, Impact of humic acid fouling on membrane performance and transport of pharmaceutically active compounds in forward osmosis, Water Research, 47 (2013) 4567-4575. 


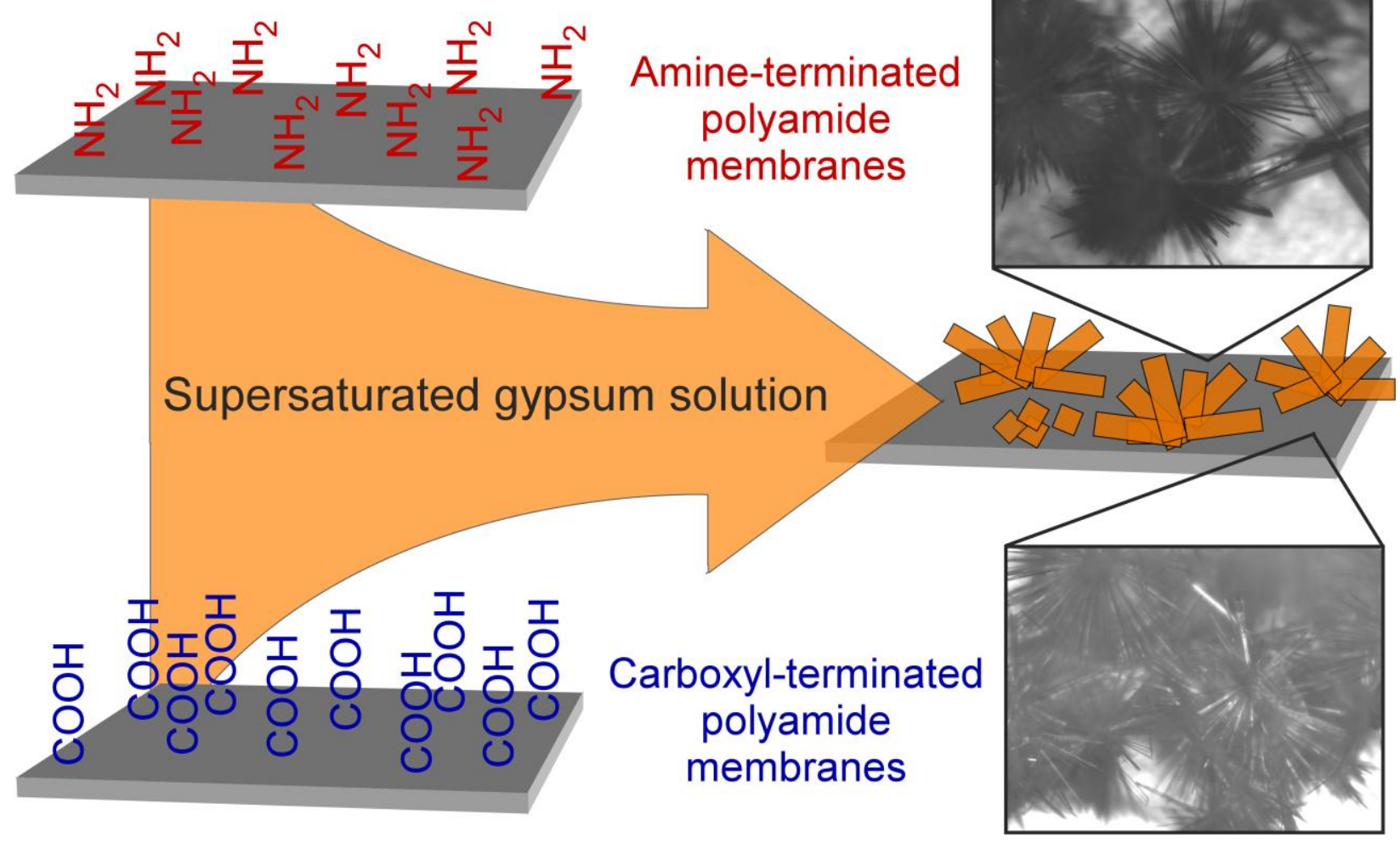

